RESEARCH ARTICLE

\title{
Maxium Sutureless Closed Haemorrhoidectomy for Symptomatic Haemorrhoids Grades III and IV: An Observational Cross-sectional Study
}

\author{
Jawad Kadhim S Al-Dhahiry*
}

Department of Surgery, College of Medicine, AL-Karama Teaching Hospital, Wasit University, Iraq

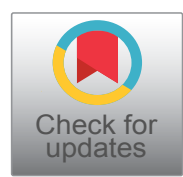

*Corresponding author: Jawad Kadhim S Al-Dhahiry, Department of Surgery, College of Medicine, AL-Karama Teaching Hospital, Wasit University, Iraq, Tel: 009647801293684,E-mail: jawaddhahiry@gmail.com

\begin{abstract}
Background: A symptomatic haemorrhoidal disease is one of the most common anorectal diseases. Haemorrhoids grades I and II can be medically treated but haemorrhoids grades III and IV are surgically treated. Although Conventional Haemorrhoidectomy Techniques $(\mathrm{CH})$ are commonly used but they are associated with some major complications. Many novel techniques have been introduced to overcome these complications such as Maxium Haemorrhoidectomy (MH).
\end{abstract}

Aims: This study aimed to assess outcomes of sutureless closed haemorrhoidectomy performed by Maxium (bipolar electrodiathermy) versus outcomes of other studies that used both, novel and conventional techniques of haemorrhoidectomy for symptomatic haemorrhoids grades III and IV.

Design of study: It was a prospective observational cross-sectional study.

Setting and duration: Department of Surgery, AL-Karama Teaching Hospital/Medical College/University of Wasit/ IRAQ, from April 2014 to September 2017.

Patients and methodology: This study included 124 consecutive patients, 86 patients $(69.4 \%)$ males and 38 patients $(30.6 \%)$ females, who underwent Maxium haemorrhoidectomy for haemorrhoids grades III and/or IV. They were assessed on the basis of the following main outcomes: intraoperative blood loss, operating time and postoperative pain scoring. The follow-up period ranged 2-6 months. This study had no mortality.

Results: Patients ages ranged from 22-82 Year (y), median was 61 year, mean $\pm S D$ was $41.02 \pm 13.75$ year and $P$-value 0.04 . Intraoperative blood loss Mean \pm SD was $4.9 \pm 1.9$ Milliliter $(\mathrm{ml})$, operating time Mean \pm SD was $16.9 \pm 4.5$ Minutes $(\mathrm{m})$, mean \pm SDs of postoperative pain scoring of Day 0 , Day 1 and Day 7 were; $5.80 \pm 1.20,3.80 \pm 0.90$ and $1.80 \pm 0.80$ respectively according to Visual Analogue Score (VAS).
Conclusion: Maxium haemorrhoidectomy is an effective surgical technique for treatment of symptomatic haemorrhoids of grades III and IV. It results in less intraoperative blood loss, short operating time, less postoperative pain, less analgesia requirement and early return to normal life and activities.

\section{Keywords}

Conventional haemorrhoidectomy, Sutureless closed haemorrhoidectomy, Diathermic device, LegaSure haemorrhoidectomy, Sutureless technique

\section{Introduction}

Haemorrhoids are dilated vasculopathic structures that cushion the anal canal. Haemorrhoidectomy is a gold standard surgical treatment of symptomatic haemorrhoids grades III and IV [1].

Haemorrhoids are clinically graded as in Table 1 (page 310) [2].

The incidence rate of symptomatic haemorrhoids ranges from 4.4 to $36.4 \%$ of the general population [3]. Etiologic factors of haemorrhoidal disease include: constipation, pregnancy, increased intraabdominal pressure with obstruction of venous return, diarrhea, prolonged straining, aging, and abnormalities of internal anal sphincter [4].

Table 1: Clinical grading of haemorrhoids.

Grade I Prominent haemorrhoidal vessels but no prolapse.

Grade II Prolapse with Valsalva but spontaneously reduce.

Grade III Prolapse with Valsalva but require manual reduction.

Grade IV Chronically prolapse, manual reduction is ineffective.

Citation: Al-Dhahiry JKS (2018) Maxium Sutureless Closed Haemorrhoidectomy for Symptomatic Haemorrhoids Grades III and IV: An Observational Cross-sectional Study. Int J Surg Res Pract 5:062. doi.org/10.23937/2378-3397/1410062

Received: December 22, 2017: Accepted: February 05, 2018; Published: February 07, 2018

Copyright: (c) 2018 Al-Dhahiry JKS. This is an open-access article distributed under the terms of the Creative Commons Attribution License, which permits unrestricted use, distribution, and reproduction in any medium, provided the original author and source are credited. 
Symptomatic haemorrhoids are one of the commonest surgical conditions that population suffers from. Haemorrhoids of grades I and II are usually treated conservatively by rubber band ligation, sclerotherapy, cryotherapy or photocoagulation. Symptomatic haemorrhoids of grades III and IV usually necessitate surgical intervention. Traditional haemorrhoidectomy performed by Milligan-Morgan technique (open haemorrhoidectomy) or Ferguson technique (closed haemorrhoidectomy) are commonly used techniques [5].

Dae Ro Lim, et al. "Despite these two techniques are very effective in treatment of grades III and IV haemorrhoids, but complications such as perioperative anorectal bleeding, surgical-site anal pain, anal stenosis, and faecal incontinence can occur after surgery. These complications will increase the patient's hospital stay, delay the return to normal life and the workplace after surgery and may increase the rate hospital revisits. Thus, novel surgical equipments, surgical techniques and supportive therapies have been introduced to overcome these postoperative complications" (page 111) [6].

Akira Tsunoda, et al. "Recent advances in the instrumental technology produced novel devices including bipolar electrothermal device, ultrasonic scalpel, and circular stapler providing effective alternatives that resulted in less postoperative pain and perioperative blood loss" (page 148) [7].

Using these devices in haemorrhoidectomy resulted in: less postoperative pain and less perioperative blood loss compared with haemorrhoidectomies performed with conventional surgical techniques [8-10].

Maxium is a new vessel sealing system has been recently introduced (produced by KLS martin group, Germany). It is a bipolar electrosurgical device that gives a combination of pressure and radiofrequency. It seals blood vessels of diameters up to $6 \mathrm{~mm}$ by denaturating elastin and collagen from the vessel wall and surrounding connective tissue with a minimal collateral thermal damage limited to 2 millimeters over the surgical site. The coagulation zone can withstand up to 3 times the systolic blood pressure.

This limited spread of thermal energy decreases the postoperative pain and anal spasm allowing to perform a bloodless haemorrhoidectomy with low postoperative pain and fast healing [11]. Bipolar diathermy haemorrhoidectomy is a sutureless closed haemorrhoidectomy because the coagulum zone is just divided where anal mucosal edges are fused [7].

The aim of this study was to assess outcomes of sutureless closed haemorrhoidectomy performed with Maxium versus outcomes of other studies that used both, novel and conventional techniques of haemorrhoidectomy for symptomatic haemorrhoids grades III and IV.

\section{Patients and Methods}

This study started after approval of the Ethical Committee of Medical College/Wasit University/Iraq on the study proposal on March 2014.

This study recruited 124 consecutive patients underwent a sutureless closed haemorrhoidectomy with Maxium for grades III and IV symptomatic haemorrhoids at AL-Karama Teaching Hospital/College of Medicine/Wasit University/IRAQ during the period from April 2014 to September 2017. The patients were 86 males (69.4\%) and 38 females (30.6\%).

Inclusion criteria were: Symptomatic haemorrhoids grades III and IV.

Exclusion criteria included: Grades I and II hemorrhoids, pregnancy, liver cirrhosis, haemorrhagic diseases, inability to give written informed consent [7], preexisting anorectal disease, previous anorectal surgical procedure, thrombosed haemorrhoids, inflammatory bowel disease and unwilling patients [12].

All patients underwent a proper preoperative evaluation including: history taking, thorough physical examination and investigations that included: chest X-rays, electrocardiography and laboratory investigations (complete blood picture, PT, PTT, fasting blood sugar, blood urea, serum creatinine, Hepatitis $B$, Hepatitis $C$ and HIV. Also anoproctoscopic examination was preoperatively performed. Jinn-Shiun Chen, et al. "Colonoscopy was performed in those aging over 50 years to rule out colonic cancer" [4]. The study patients had a routine preoperative anesthesiologic assessment. The patients were advised to use laxidyle (laxative) suppository at night before surgery. They were admitted to the hospital at morning of surgery. Every patient was informed about the nature of this haemorrhoidectomy technique and its complications. A signed consent was obtained from each patient. Prophylactic antibiotics were intravenously injected at time of induction of anesthesia (Cefotaxime vial $1 \mathrm{gm}$ day/8-hourly for one day or Amikacin vial $500 \mathrm{mg} / 12$-hourly for one day.

According to the preoperative anesthesiologic assessment, some patients were given spinal or caudal anesthesia while the others were given general anesthesia when spinal or caudal anesthesia failed. They were placed in lithotomy position. An anoscope was put into the anal canal to have surgical field with good exposure. Each haemorrhoidal mass was lifted with two pairs of Alles's clamp to lift them away from the intenal anal sphincter and the haemorrhoidal pedicle was clamped with a curved arterial clamp. The mucocutaneous junction of the haemorrhoidal mass was incised with monopolar electrocautery while the haemorrhoidal mass and pedicle were coagulated with Maxium after being lifted away from the internal anal sphincter. Then, the coagulum zone was divided with scissors leaving dry and closed haemorrhoidal bed. A small piece of gauze 
Table 2: Patients demographic features.

\begin{tabular}{|c|c|c|c|c|c|c|c|}
\hline \multirow[t]{2}{*}{ Sex } & \multicolumn{2}{|c|}{ Patients } & \multicolumn{5}{|c|}{ Age statistics/year } \\
\hline & No $=$ & $\%$ & Minimum & Maximum & Median & Mean \pm SD & P-Value \\
\hline Male & 86 & 69.4 & 21 & 75 & - & - & \\
\hline Female & 38 & 30.6 & 22 & 82 & - & - & 0.04 \\
\hline Total & 124 & 100 & $21 y$ & $82 y$ & $61 y$ & $41.02 \pm 13.75 y$ & \\
\hline
\end{tabular}

$\mathrm{y}=$ year.

Table 3: Descriptive statistics of results of this study.

\begin{tabular}{|l|l|l|l|l|l|}
\hline Study variables & No $=$ & Minimum & Maximum & Median & Mean \pm SD \\
\hline Age/y & 124 & 21 & 82 & 61 & $41.02 \pm 13.75$ \\
\hline Intraoperative blood loss/mI & 124 & 2 & 10 & 8 & $4.91 \pm 1.90$ \\
\hline Operating time/m & 124 & 10 & 27 & 17 & $16.92 \pm 4.46$ \\
\hline Postoperative pain of Day 0 & 124 & 3 & 8 & 5 & $5.81 \pm 1.23($ VSA) \\
\hline Postoperative pain of Day 1 & 124 & 2 & 6 & 4 & $3.83 \pm 0.89$ (VSA) \\
\hline Postoperative pain of Day 7 & 124 & 1 & 4 & 2 & $1.83 \pm 0.77$ (VSA) \\
\hline Postoperative analgesia injections (Day 0)/amp & 124 & 1 & 2 & 1 & $1.4 \pm 0.5$ \\
\hline Postoperative analgesia oral tablets (Days 1-7) & 124 & 6 & 16 & 10 & $10.56 \pm 2.05$ \\
\hline
\end{tabular}

VSA = Visual Analogue Score.

covered with Xylocaine (lidocaine $\mathrm{HCl}$ ) gel $5 \%$ was left in the anal canal at the end of the procedure.

In this study no suture material was used because the coagulum created by Maxium had fused the nearby anal mucosa. The patients were asked to document their pain score from day 0 until the $7^{\text {th }}$ postoperative day on a self administered Visual Analog Scale (VAS) [5] that scores from 0 to 10 . Patients were weekly evaluated for the first one month then monthly for five months after haemorrhoidectomy. The patient demographics, intraoperative blood loss, operating time, postoperative pain scoring, postoperative analgesia requirement and quality of life were recorded [11,13]. The blood loss was calculated by substracting the dry weight of the used gauzes from their wet weights.

Dae Ro Lim, et al. "Major blood loss was defined as that required intensive treatment (including blood transfusion, reoperation) or close monitoring. Minor blood loss was defined as that did not need monitoring with minimal bleeding after defecation" (page112) [6].

The operating time was measured from applying first Alles's clamp to grasp the haemorrhoidal mass to last second of insertion of a wick into the anal canal [11]. To relieve the postoperative pain in postoperative day 0 , each patient was given one ampoule or more of paracetamol (acetaminophen). In the subsequent 5-7 postoperative days, the patient was given Norgesic (aspirin/ caffeine/orphenadrine) oral tablets $500 \mathrm{mg} / 8$-hours. Also the patients were recommended to take sitz baths 2-3 times/day.

Data of this study were statistically analysed using IBM SPSS ver. 22.0 (IBM Co., Armonk, NY, USA). Categorical variables were analyzed using the Chi-Square or Fisher exact test, and continuous variables were analyzed using the Student t-test or Mann-Whitney U rank test. P-values of less than 0.05 were statistically significant.

\section{Results}

The results of this study were statistically analysed and tabulated in the following Table 2 and Table 3:

This study recruited 124 consecutive patients who underwent a sutureless closed haemorrhoidectomy with Maxium for symptomatic haemorrhoids grades III and IV. Demographic distribution of these patients was as following: 86 males (69.4\%), 38 females (30.6\%) and P-value $=0.04$. Patients' ages ranged 21-82y, median was 61y and Mean \pm SD was $41.02 \pm 13.75 y$ (Table 2).

Intraoperative blood loss of this study ranged 2-10 $\mathrm{ml}$, median was $6.1 \mathrm{ml}$ and Mean $\pm \mathrm{SD}$ was $4.9 \pm 1.9$ $\mathrm{ml}$. The operating time of this study ranged $10-27 \mathrm{~m}$, median was $17 \mathrm{~m}$ and Mean \pm SD was $16.9 \pm 4.5 \mathrm{~m}$. Postoperative pain scorings of postoperative days; Day 0 , Day 1 and Day 7 were as following: Day 0 pain scoring ranged 3-8 with a median of 5 and Mean \pm SD of $5.8 \pm$ 1.2, Day 1 ranged 2-6 with a median of 4 and Mean \pm SD of $3.8 \pm 0.9$ and Day 7 pain scoring ranged 1-4 with a median of 2 and Mean \pm SD of $1.8 \pm 0.8$. Postoperative analgesia injections (paracetamol) in Day 0 ranged 1-2 amp with median of one amp and Mean \pm SD of $1.4 \pm$ 0.5 amp. Postoperative analgesia (Norgesic oral tablets) during postoperative Days 1-7 ranged 6-16 tablets with a median of 10 tablets and Mean \pm SD of $10.56 \pm 2.05$ tab (Table 3).

\section{Discussion}

Conventional haemorrhoidectomy techniques such as Milligan-Morgan open haemorrhoidectomy, Ferguson closed haemorrhoidectomy and diathermy haemorrhoidectomy are very appropriate surgical techniques for treatment grades III-IV haemorrhoids. However, these conventional surgical techniques are accompanied by complications such as postoperative pain, anorectal bleeding, anal stenosis and anal incontinence [6].

Recently haemorrhoidectomies performed with cir- 
cular staplers and other newly developed equipments, have been reported to result in less postoperative pain, less anorectal bleeding, less complications rates, shorter operating times, and shorter hospital stays $[6,14]$.

This study recruited 124 consecutive patients who underwent a sutureless closed haemorrhoidectomy with Maxium for symptomatic haemorrhoids grades III and IV. Demographic distribution of these patients was as following; 86 males (69.4\%), 38 females $(30.6 \%)$ and $p$-value $=$ 0.04 . Patients' ages ranged $21-82 y$, median was $61 y$ and mean \pm SD was $41.02 \pm 13.75 y$. Maurizio Gentile, et al. [14] study included 52 patients with age mean of $47 y$ for diathermy, 48y for LigaSure patients and overall range 19-80y. These results are rather similar to my study demographic results. In their study, male: female ratio was Diathermy, LegaSure 1.4, 1.3 respectively (statistically not significant) while this study resulted, male: female ratio of 2:1 that was statistically significant ( $p$-value $=0.04$ )

Regarding intraoperative blood losses, the studies $[5,11,12,15-17]$ reported intraoperative blood losses of LH groups: $6.53 \pm 2.90 \mathrm{ml}, 17.0 \pm 3.6 \mathrm{ml}, 11.5 \pm 2.5 \mathrm{ml}$, $51.92 \mathrm{ml}$ respectively, while intraoperative blood losses of $\mathrm{CH}$ groups were; $28.42 \pm 7.32 \mathrm{ml}, 26.56 \pm 11.30 \mathrm{ml}$, $22.0 \pm 4.5 \mathrm{ml}, 70.34 \mathrm{ml}$ respectively. This $\mathrm{MH}$ study had intraoperative blood loss of $4.9 \pm 1.9 \mathrm{ml}$. These results revealed that $\mathrm{LH}$ technique is associated with less intra- operative blood loss when compared with conventional techniques. These results also revealed that $\mathrm{MH}$ had the least intraoperative blood loss in the two groups of the surgical techniques (Table 4).

Regarding operating time, the studies $[5,11,12,13,15$ 18] reported operating time of LH groups: $11.22 \mathrm{~m}$, $10.75 \pm 6.70 \mathrm{~m}, 12.5 \pm 3.0 \mathrm{~m}, 18 \mathrm{~m}, 22.3 \mathrm{~m}, 24 \pm 8.0$ $\mathrm{m}, 36.6 \mathrm{~m}, 7.6 \pm 2.5 \mathrm{~m}$ respectively, while operating times of their $\mathrm{CH}$ groups were; $28.42 \mathrm{~m}, 32.72 \pm 9.72$ $\mathrm{m}, 29.0 \pm 5.2 \mathrm{~m}, 36 \mathrm{~m}, 27.4 \mathrm{~m}, 41 \pm 12 \mathrm{~m}, 52.5 \mathrm{~m}, 18.9$ \pm 4.5 respectively. Despite a significant variation in the operating time between these studies but, LH groups were generally having shorter operating time than $\mathrm{CH}$ groups. Maxium haemorroidectomy had an operative time of $16.9 \pm 4.5 \mathrm{~m}$, shorter than that of LH groups of the studies $[13,15-17]$ but longer than that of LH groups of the studies $[5,11,12,17]$. Maxium haemorroidectomy operating time was shorter than operating times of $\mathrm{CH}$ groups of all studies above (Table 4).

Regarding postoperative pain scoring, the studies $[5,11,12,13,15-18]$ reported that the postoperative pain scores of $\mathrm{LH}$ groups were less than those of $\mathrm{CH}$ groups. Maxium haemorroidectomy had postoperative pain score representing an average score of the $\mathrm{LH}$ groups pain scores but shorter than pain scores of $\mathrm{CH}$ groups of the studies above (Table 4).

Table 4: Comparison of this study results versus those of other studies.

\begin{tabular}{|c|c|c|c|c|}
\hline Study/Year & Surgical technique & Intraop blood loss/ml & Operating time/m & $\begin{array}{l}\text { Postop. pain score of } \\
\text { days } 0,1 \text { and } 7\end{array}$ \\
\hline \multirow[t]{2}{*}{ Wagih M Ghnnam [11]/2017 } & LigaSure & $6.53 \pm 2.90$ & 11.22 & $-, 4.6,3.7$ \\
\hline & Conventional Tech & $28.40 \pm 7.30$ & 28.42 & $-, 6.4,4.2$ \\
\hline \multirow[t]{2}{*}{ Serkan Teksöz, et al. [12]/2011 } & LigaSure & $17.00 \pm 3.60$ & $10.80 \pm 6.70$ & $\begin{array}{l}\text { Day } 1 \\
3.25 \pm 3.00\end{array}$ \\
\hline & Conventional Tech & $26.60 \pm 11.30$ & $32.72 \pm 9.70$ & $\begin{array}{l}\text { Day } 1 \\
6.6 \pm 2.2\end{array}$ \\
\hline \multirow[t]{2}{*}{ Rahul Khanna, et al. [5]/2010 } & LigaSure & $11.50 \pm 2.50$ & $12.50 \pm 3.00$ & $4.1,3.2,1.2$ \\
\hline & Conventional Tech & $22.00 \pm 4.50$ & $29.00 \pm 5.20$ & $6.8,5.2,1.4$ \\
\hline \multirow[t]{2}{*}{ Milito G, et al. [13]/2017 } & Radiofrequency & - & 18 & $-, 3.4,1.9$ \\
\hline & Conventional Tech & - & 36 & $-, 5.4,2.4$ \\
\hline \multirow[t]{2}{*}{ Maurizio Gentile, et al. [15]/2011 } & LigaSure & - & 22.3 & $\begin{array}{l}\text { Days } 1,7 \\
3.7,1.6\end{array}$ \\
\hline & Conventional Tech & - & 27.4 & $\begin{array}{l}\text { Days } 1,7 \\
4.0,2.0\end{array}$ \\
\hline \multirow[t]{2}{*}{$\begin{array}{l}\text { Luana Franceschilli, et al. } \\
\text { [16]/2011 }\end{array}$} & LigaSure & - & $24.00 \pm 8.0$ & $\begin{array}{l}1^{\text {st }} \text { week } \\
4.6 \pm 2.4\end{array}$ \\
\hline & Conventional Tech & - & $41.0 \pm 12.0$ & $\begin{array}{l}1^{\text {st }} \text { week } \\
5.2 \pm 1.9\end{array}$ \\
\hline \multirow[t]{2}{*}{ Bakhtiar N, et al. [17]/2016 } & LigaSure & 51.92 & 36.60 & $4.6,3.6,1.3$ \\
\hline & Conventional Tech & - & 52.5 & $6.7,5.4,2.4$ \\
\hline \multirow[t]{2}{*}{ Ghimire $P$, et al. [18]/2014 } & LigaSure & - & $7.6 \pm 2.5$ & $3.8 \pm 0.6$ \\
\hline & Conventional Tech & - & $18.9 \pm 4.5$ & $7.4 \pm 0.7$ \\
\hline This Study & Maxium & $4.9 \pm 1.9$ & $16.9 \pm 4.5$ & $\begin{array}{l}5.8 \pm 1.2- \\
3.8 \pm 0.9 \\
1.8 \pm 0.8\end{array}$ \\
\hline
\end{tabular}


Regarding postoperative analgesia and sedation requirements, Wagih M Ghnnam [11] reported that for LH group, mean of required analgesics was NSAIDs $=3$ injections, tablets $=19.5 / 14$ days, while for $\mathrm{CH}$ group mean of required analgesics and sedation was 3 NSAIDs, 3 doses of Pethidine and tablets $=32 / 14$ days. In my study, the required postoperative analgesics injections (Paracetamol) in Day 0 was $1.4 \pm 0.5$ amp and analgesic oral tablets (Norgesic) during postoperative days 1-7 were $10.56 \pm 2.05$ tablets. Thus, the amounts analgesia required for patients of $\mathrm{LH}$ group of study [11] and $\mathrm{MH}$ were lower that required for patients of $\mathrm{CH}$ group of study [11].

\section{Conclusion}

Maxium haemorrhoidectomy is an effective surgical procedure for symptomatic haemorrhoids of grades III and IV because it results in less blood loss, less postoperative pain, short operating time and early return to normal life and activities. Maxium haemorrhoidectomy is a cost-effective surgical procedure because the price of the equipment and its accessories can be balanced by; short operating time, less anaesthesia needed, less postoperative analgesia needed due to low postoperative pain, no suture material used and early return to work. Maxium haemorrhoidectomy is a quick and easy technique to perform haemorrhoidectomy for the surgeon and a safe and less painful procedure for the patient.

\section{Conflict of Interest}

I declare that I have no potential conflict of interest.

\section{References}

1. Davide Papis, Matías Parodi, Fernando Herrerías, Sánchez Ana, Gómez Luis, et al. (2013) Hemorroidectomía con Ligasure $^{\mathrm{TM}}$ vs diatermia convencional: Análisis retrospectivo monocéntrico. Acta Gastroenterológica Latinoamericana 43: 284-288.

2. Luis Pochet Sánchez (2014) Hemorroidectomia Convencional Vrs Ligasu Re. Revista Medica De Costa Rica Y Centroamerica Lxxi 610: 309-312.

3. Adnan Aziz, Irfan Ali, Shams Nadeem Alam, S Manzar (2008) Open Haemorrhoidectomy Versus Closed Haemorrhoidectomy: The Choice Should Be Clear. Pakstan Journal of Surgery 24: 254-257.

4. Jinn-Shiun Chen, Jeng-Fu You (2010) Current status of surgical treatment for hemorrhoids - systematic review and meta-analysis. Chang Gung Med J 33: 488-500.

5. Rahul Khanna, Seema Khanna, Shilpi Bhadani, Sanjay Singh, Ajay K Khanna (2010) Comparison of ligasure hem- orrhoidectomy with conventional ferguson's hemorrhoidectomy. Indian J Surg 72: 294-297.

6. Dae Ro Lim, Dae Hyun Cho, Joo Hyun Lee, Jae Hwan Moon (2016) Comparison of a hemorrhoidectomy with ultrasonic scalpel versus a conventional hemorrhoidectomy. Ann Coloproctol 2: 111-116.

7. Akira Tsunoda, Haruki Sada, Takuya Sugimoto, Nobuyasu Kano, Mariko Kawana, et al. (2011) Randomized controlled trial of bipolar diathermy vs ultrasonic scalpel for closed hemorrhoidectomy. World J Gastrointest Surg 3: 147-152.

8. Jayne DG, Botterill I, Ambrose NS, Brennan TG, Guillou PJ, et al. (2002) Randomized clinical trial of Ligasure versus conventional diathermy for day-case haemorrhoidectomy. Br J Surg 89: 428-432.

9. Bulus H, Tas A, Coskun A, Kucukazman M (2014) Evaluation of two hemorrhoidectomy techniques: harmonic scalpel and Ferguson's with electrocautery. Asian J Surg 37: 20-23.

10. Jayaraman S, Colquhoun PH, Malthaner RA (2006) Stapled versus conventional surgery for hemorrhoids. Cochrane Database Syst Rev 4: CD005393.

11. Wagih M Ghnnam (2017) Prospective, randomized controlled trial of ligasure ${ }^{\mathrm{TM}}$ versus conventional Hemorrhoidectomy for grade III and IV hemorrhoids. International Journal of Surgery and Medicine 3: 8-13.

12. Serkan Teksoz, Erman Aytac, Nihat Yavuz, Osman Baran Tortum, Murat Ozcan, et al. (2011) Comparison of a vessel sealing system with a conventional technique in hemorrhoidectomy. Balkan Med J 28: 189-192.

13. Milito G, Lisi G, Aronadio E, Campanelli M, Venditti D, et al. (2017) May radiofrequency be the best choice for III-IV degree hemorrhoids? Minerva Gastroenterol Dietol 63: 38-43.

14. Sgourakis G, Sotiropoulos GC, Dedemadi G, Radtke A, Papanikolaou I, et al. (2008) Stapled versus Ferguson hemorrhoidectomy: Is there any evidence-based information? Int $\mathrm{J}$ Colorectal Dis 23: 825-832.

15. Maurizio Gentile, Michele De Rosa, Gabriele Carbone, Vincenzo Pilone, FrancescaMosella, et al. (2011) LigaSure Haemorrhoidectomy versus Conventional Diathermy for IV-Degree Haemorrhoids: Is It the Treatment of Choice? ISRN Gastroenterology 2011: 467258.

16. Luana Franceschilli, Vito M Stolfi, Stefano D Ugo, Angelucci GP, Lazzaro S, et al. (2011) Radiofrequency versus conventional diathermy Milligan-Morgan hemorrhoidectomy: A prospective, randomized study. Int $\mathrm{J}$ Colorectal Dis 26: $1345-1350$.

17. Bakhtiar N, Moosa FA, Jaleel F, Qureshi NA, Jawaid M (2016) Comparison of hemorrhoidectomy by LigaSure with conventional Milligan Morgan's hemorrhoidectomy. Pak J Med Sci 32: 657-661.

18. Ghimire P, Gurung NV, Upadhaya PK, Shrestha S, Gurung A, et al. (2014) Comparison of hemorrhoidectomy by LigaSure with conventional Milligan Morgan's hemorrhoidectomy. NJMS 03: 121-123. 